УДК 581.9:581.19

\title{
СОСТАВ АНТОЦИАНОВ ПЛОДОВ ЧЕРНИКИ ОБЫКНОВЕННОЙ, БРУСНИКИ ОБЫКНОВЕННОЙ И КЛЮКВЫ ОБЫКНОВЕННОЙ КРАСНОЯРСКОГО КРАЯ ПО ДАННЫМ ВЭЖХ
}

\author{
(C) С.А. Полина, А.А. Ерремов* \\ Сибирский фредеральный университет, пр. Свободный, 79, Красноярск, \\ 660041 (Россия), e-mail: AEfremov@sfu-kras.ru
}

В работе приведены данные об антоциановом составе мороженых плодов черники обыкновенной (Vaccinium myrtillus L.), брусники обыкновенной (Vaccinium vitis idaea L.), клюквы обыкновенной (Vaccinium oxycoccus L.), coбранных на территории Енисейского района Красноярского края. Методом ВЭЖХ с УФ детектированием определен антоциановый состав данных ягод. Проведено сравнение качественного состава и количественного содержания антоцианов. ВЭЖХ

Ключевые слова: Vaccinium myrtillus L., Vaccinium vitis idaea L., Vaccinium oxyсоссиs L., экстракт, антоцианы,

\section{Введение}

На сегодняшний день научной медициной недостаточно широко используются многие лекарственный растения, так как являются малоизученными. При этом фармацевтическая практика постоянно требует увеличения ассортимента и количества лекарственного растительного сырья. Это особенно актуально для регионов, удаленных от Центральной России, - Восточной Сибири, Якутии и Дальнего Востока [1].

Ценность дикорастущих ягодных растений состоит в том, что они имеют относительно высокую приспособленность к местным условиям и проявляют иммунитет ко многим заболеваниям. В связи с этим дикорастущие ягоды по содержанию многих биологически активных веществ, превосходят культурные. Также следует отметить, что дикорастущие ягоды в период роста не обрабатывают химическими препаратами [2].

Ягоды брусники и клюквы широко применяются в народной медицине в качестве жаропонижающего, мочегонного, стимулирующего и тонизирующего средства, для профилактики простудных заболеваний и поднятия иммунитета. В литературе приводится следующий состав антоцианов брусники и клюквы обыкновенной - цианидин-3-галактозид, пеонидин-3-галактозид, цианидин-3-арабинозид, пеонидин-3арабинозид, пеонидин-3-арабинозид; брусники - цианидин-3-галактозид, цианидин-3-глюкозид [3]. В других источниках антоцианы клюквы главным образом представлены цианидин-3-глюкозидом, цианидин-3арабинозидом, пеонидин-3-галактозидом, пеонидин-3-арабинозидом и пеонидин-3-глюкозидом [4, 5].

Пищевая ценность ягод черники определяется наличием в них витаминов и витаминоподобных веществ, макро- и микроэлементов. Плоды черники содержат большое количество антоцианов - гликозидов дельфинидина и мальвидина; дубильные вещества конденсированной природы; сахара; органические кис-

Полина Светлана Алексеевна - аспирант кафедры органической и аналитической химии, e-mail: Demi-2704@yandex.ru

Ефремов Александр Алексеевич - заведующий лабораторией хроматографических методов анализа центра коллективного пользования, доктор химических наук, професcop, e-mail: AEfremov@sfu-kras.ru лоты (лимонную, яблочную и др.); аскорбиновую кислоту, каротин, витамины В1, Р, пектиновые вещества, соли марганца и железа [6, 7].

Антоцианы - это водорастворимые растительные пигменты отвечающие за голубую, пурпурную и красную окраски различных вегетативных частей растений. В растительных клетках они присутствуют

\footnotetext{
* Автор, с которым следует вести переписку.
} 
в вакуолях в виде гранул различных размеров. Антоцианы относятся к большой группе соединений - флавоноидам. Антоцианидины, антоцианины - агликоны антоцианов, гидроксипроизводные 2-фенилхромена. Антоцианидины состоят из ароматического кольца А, соединенного с гетероциклическим кольцом С, которое содержит кислород и соединено посредством углерод-углеродной связи с третьим ароматическим кольцом В (рис. 1). Антоцианидины очень нестабильны, потому что они обычно присутствуют в гликозидных формах. В гликозидах антоцианидинов остаток сахара присоединяется в случаях моногликозидов к углеродному атому в положении 3 кольца С, а в случае дигликозидов - в положении 5 кольца А. Из сахаров, входящих в молекулу антоцианов, главным образом встречается глюкоза, реже - рамноза, арабиноза и галактоза. В таких формах они известны как антоцианы. Найдено более 500 различных антоцианов и 23 антоцианидина. Наиболее распространенные антоцианидины в природе пеларгонидин, пеонидин, цианидин, мальвидин, петунидин и дельфинидин. Наиболее распространенный антоцианом является цианидин3-глюкозид [8].

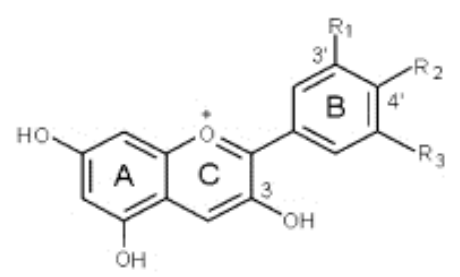

Рис. 1. Структурная формула антоцианидинов

\begin{tabular}{c|c|c|c}
\hline Anthocyanidin & $\mathrm{R}_{1}$ & $\mathrm{R}_{2}$ & $\mathrm{R}_{3}$ \\
\hline Pelagonidin $(\mathrm{Pg})$ & $\mathrm{H}$ & $\mathrm{OH}$ & $\mathrm{H}$ \\
Cyanidin $(\mathrm{Cy})$ & $\mathrm{OH}$ & $\mathrm{OH}$ & $\mathrm{H}$ \\
Delphinidin $(\mathrm{Dp})$ & $\mathrm{OH}$ & $\mathrm{OH}$ & $\mathrm{OH}$ \\
Peonidin $(\mathrm{Pn})$ & $\mathrm{OMe}$ & $\mathrm{OH}$ & $\mathrm{H}$ \\
Petunidin $(\mathrm{Pt})$ & $\mathrm{OMe}$ & $\mathrm{OH}$ & $\mathrm{OH}$ \\
Malvidin $(\mathrm{Mv})$ & $\mathrm{OMe}$ & $\mathrm{OH}$ & $\mathrm{OMe}$ \\
\hline
\end{tabular}

Цвет антоцианов зависит от природы металла, который входит в их комплекс. С железом антоцианы дают синюю, с молибденом фиолетовую, с никелем белую, с кальцием пурпурную окраску. Цвет антоцианов также зависит от рН среды, в зависимости от которого появляется окраска, образуемая псевдооснованиями. Так, при подкислении антоцианы окрашиваются в красный цвет, а при подщелачивании приобретают голубоватый, а в сильно щелочной среде зеленоватый цвет [9].

Антоцианы, как и флавоноиды, обладают антиокислительной активностью, которой придают большое значение при лечении рака, атеросклероза, гипертонической болезни и других не менее распространенных и тяжелых заболеваний $[9,10]$.

Качественный состав антоцианов, как правило, специфичен для конкретного вида растений и довольно стабилен [10]. Однако он зависит от особенностей и условий произрастания растения [11] .

Известно, что состав БАВ и уровень их накопления зависят от почвенно-климатических условий их произрастания. Поэтому изучение антоцианового состава ягод брусники, черники и клюквы ранее не изученных территорий является важной и актуальной задачей.

В связи с этим целью данной работы являлось определить и сравнить методом ВЭЖХ состав антоцианов черники обыкновенной, клюквы обыкновенной и брусники обыкновенной Красноярского края.

\section{Экспериментальная часть}

Исследуемые в данной работе ягоды черники обыкновенной, клюквы обыкновенной и брусники обыкновенной собраны на территории Енисейского района Красноярского края. Сырье собиралось и хранилось по фармакопее и ГОСТу [12,13].

Экстракция проводилась 60\%-ным спиртом, содержащим $1 \% \mathrm{HCl}$, на кипящей водяной бане в течение 90 мин. Соотношение сырье : экстрагент - $1: 50$.

Спиртовые экстракты плодов черники, клюквы и брусники по отдельности хроматографировали на жидкостном хроматографе Agilent 1200 при следующих условиях: колонка Luna 5u C18(2) 100A (250×4,6 mm 5 мкм); температура термостата $-25{ }^{\circ} \mathrm{C}$; длина волны детектирования - 543 нм; подвижная

Таблица 1. Режим элюирования

\begin{tabular}{c|c}
\hline Время, мин & $\begin{array}{c}\text { Содержание ацетони- } \\
\text { трила, об. } \%\end{array}$ \\
\hline $0-10$ & $1-15$ \\
$10-30$ & $15-25$ \\
$30-60$ & $25-60$
\end{tabular}

фаза: ацетонитрил; 0,01\% раствор фосфорной кислоты в воде; режим элюирования - градиентный (табл. 1). Сбор данных, обработка хроматограмм и спектров поглощения проводили с помощью программы AgilentChemStation. Пики идентифицировали по литературным данным, сопоставляя времена удерживания на аналогичных колонках, и УФ-спектрам индивидуальных компонентов $[8,9$, 
14-17]. Для подтверждения достоверности идентификации снимали растворы стандартных образцов дельфинидин-3-глюкозида, цианидин-3-глюкозида и мальвидин-3-галактозида при аналогичных условиях. Сравнивали времена удерживания стандартных веществ с временами удерживания данных веществ, обнаруженных в экстрактах. Электронные спектры в УФ и видимой области спектра фиксировали на спектрофотометре «Shimadzu-1700» в кюветах толщиной 10 мм.

\section{Обсуждение результатов}

На спектрофотометре UV1700 «Shimadzu» PharmaSpec были сняты спектры поглощения спиртового экстракта клюквы, брусники и черники (рис. 2). Полученные кривые поглощения спиртового экстракта

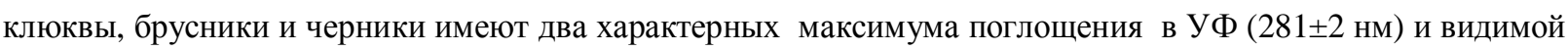

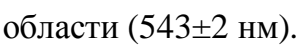

В экстракте черники обыкновенной Красноярского края обнаружено 17 компонентов (рис. 3), представляющих собой антоцианы, 15 из них идентифицированы (табл. 2). Антоцианы с наибольшим процентным содержанием: дельфинидин-3-глюкозид $(8,1 \%)$, цианидин-3-галактозид $(12,7 \%)$, дельфинидин-3арабинозид $(15,9 \%)$, петунидин-3-арабинозид (8,2\%), мальвидин-3-галактозид $(15,7 \%)$.

Рис. 2. Спектры поглощения экстракта клюквы в 60\%-ном этиловом спирте, содержащего $1 \% \mathrm{HCl}(1)$, экстракта брусники (2) и экстракта черники Красноярского края в аналогичном растворителе (3)
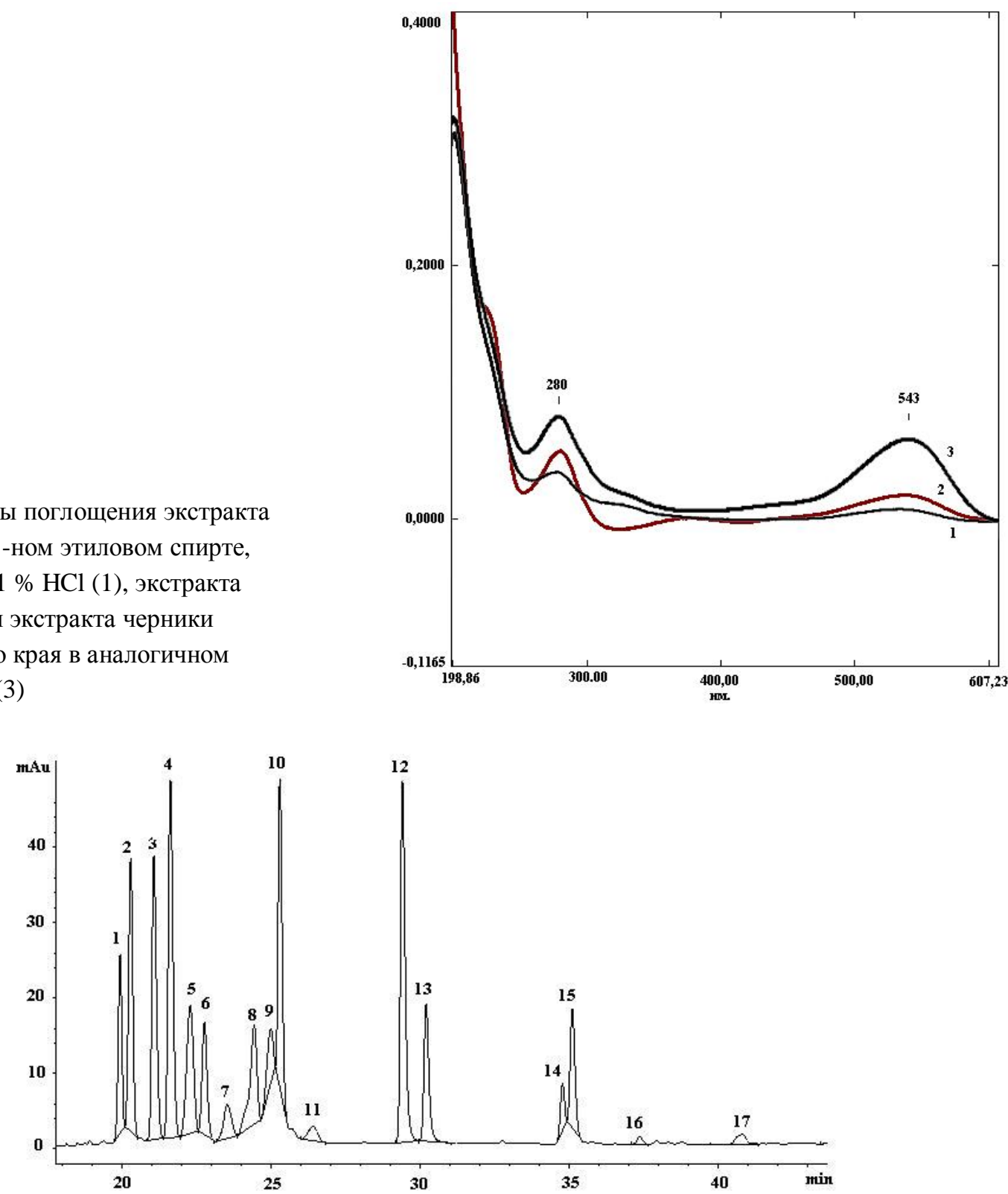

Рис. 3. Хроматограмма антоцианов плодов черники обыкновенной 
Таблица 2. Антоцианы в плодах черники обыкновенной Красноярского края

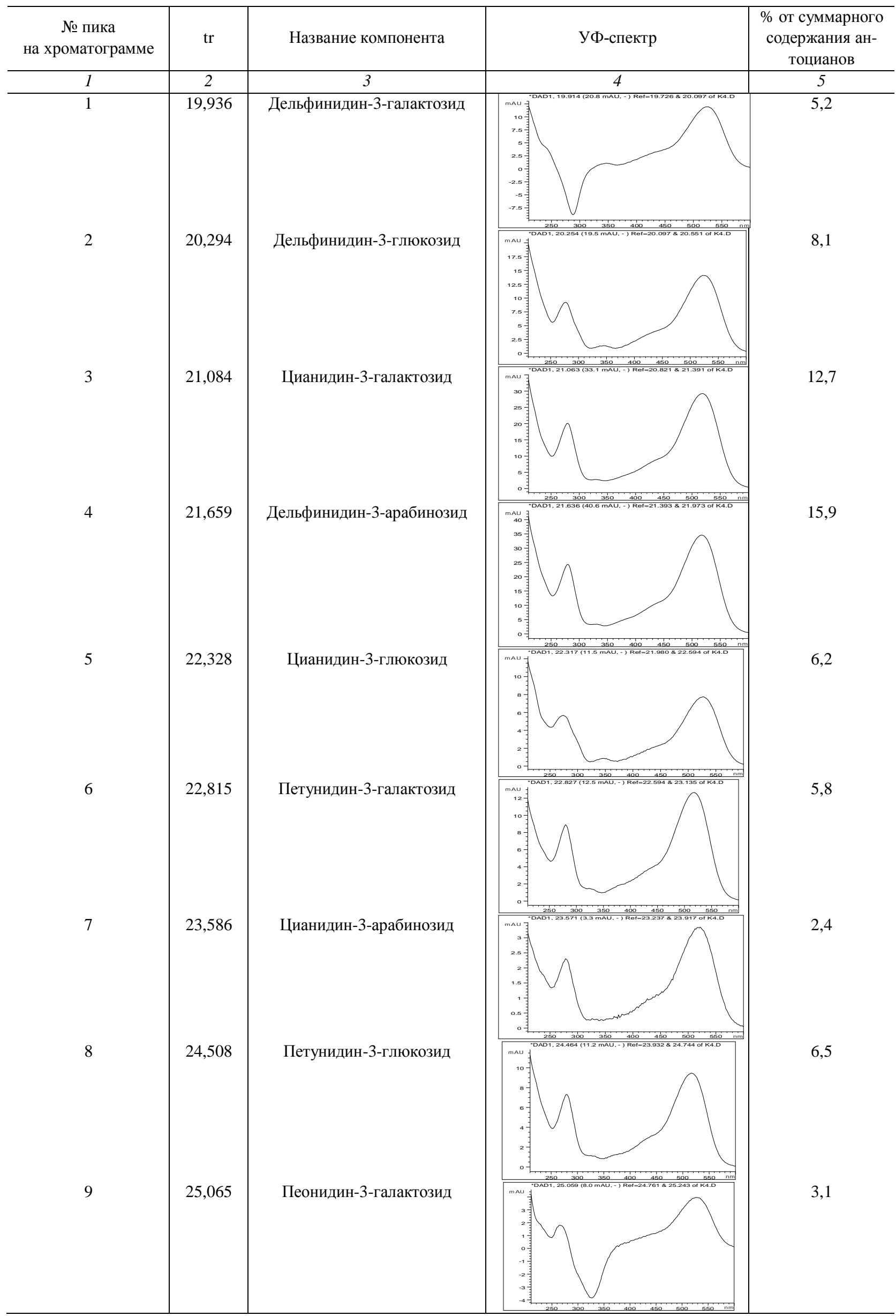


Окончание таблицы 2

\begin{tabular}{|c|c|c|c|c|}
\hline 1 & 2 & 3 & 4 & 5 \\
\hline 10 & 25,408 & Петунидин-3-арабинозид & ${ }^{\mathrm{mau}} \mathrm{Z}$ & 8,2 \\
\hline 11 & 26,497 & Пеонидин-3-глюкозид & 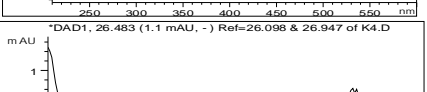 & 1,1 \\
\hline 12 & 29,596 & Мальвидин-3-галактозид & 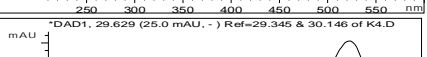 & 15,7 \\
\hline 13 & 30,397 & Пеонидин-3-арабинозид & 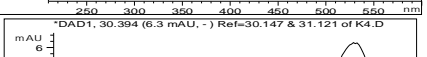 & 4,1 \\
\hline 14 & 35,053 & Мальвидин-3-глюкозид & $\begin{array}{ll}\text { mau } \\
\end{array}$ & 1,1 \\
\hline 15 & 35,378 & Мальвидин-3-арабинозид & 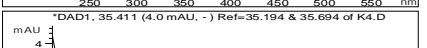 & 2,7 \\
\hline 16 & 37,521 & не идентифицирован* & 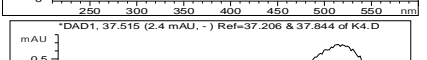 & 0,4 \\
\hline 17 & 40,950 & не идентифицирован* & 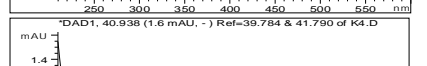 & 0,8 \\
\hline & & & Итого & 100 \\
\hline
\end{tabular}

*При отсутствии стандартных образцов однозначная идентификация затруднена.

В экстракте брусники обыкновенной Красноярского края обнаружено четыре компонента (рис. 4), представляющих собой антоцианы, три из них идентифицированы (табл. 3). Антоцианы с наибольшим процентным содержанием: цианидин-3-галактозид (39,3\%), мальвидин-3-галактозид $(51,4 \%)$. 


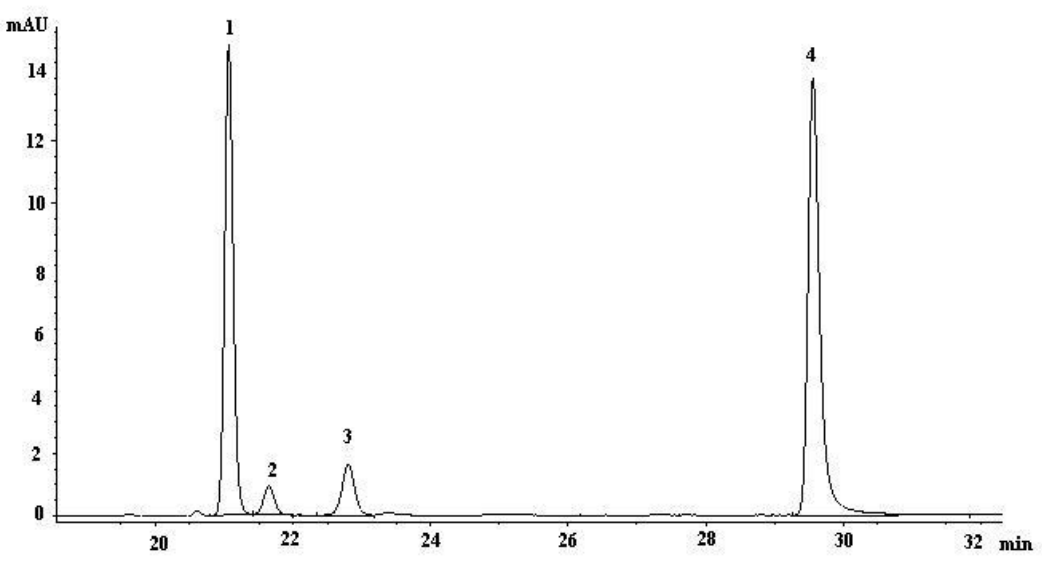

Рис. 4. Хроматограмма антоцианов плодов брусники обыкновенной

Таблица 3. Антоцианы в плодах брусники обыкновенной Красноярского края

\begin{tabular}{|c|c|c|c|c|}
\hline $\begin{array}{c}\text { № пика } \\
\text { на хроматограмме }\end{array}$ & $\operatorname{tr}$ & Название компонента & УФ-спектр & $\begin{array}{l}\% \text { от суммарного со- } \\
\text { держания антоцианов }\end{array}$ \\
\hline 1 & 21,066 & $\begin{array}{c}\text { Цианидин-3- } \\
\text { галактозид }\end{array}$ & 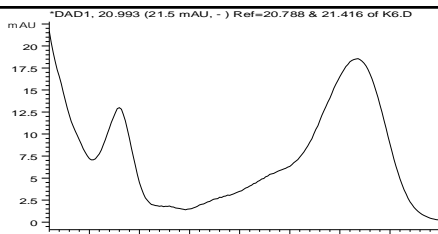 & 39,3 \\
\hline 2 & 21,650 & не идентифицирован* & mAU & 3,0 \\
\hline 3 & 22,804 & $\begin{array}{c}\text { Петунидин-3- } \\
\text { галактозид }\end{array}$ & maU & 6,3 \\
\hline 4 & 29,561 & $\begin{array}{c}\text { Мальвидин-3- } \\
\text { галактозид }\end{array}$ & $\begin{array}{ll}250 \\
20\end{array}$ & 51,4 \\
\hline & & & Итого & 100 \\
\hline
\end{tabular}

*При отсутствии стандартных образцов однозначная идентификация затруднена.

В экстракте клюквы обыкновенной Красноярского края обнаружено 10 компонентов (рис. 5), представляющих собой антоцианы, три из них идентифицированы Антоцианы с наибольшим процентным содержанием: цианидин-3-галактозид (номер пика на хроматограмме 1) (8,6\%), петунидин-3-галактозид (номер пика на хроматограмме 3) (14,7\%), мальвидин-3-галактозид (номер пика на хроматограмме 6) $(27,4 \%)$, антоциан (номер пика на хроматограмме 8 ) (31,3\%). Видно, что максимальное содержание у вещества, дающего пик №8. Представляет интерес идентифицировать данное вещество, но в отсутствие стандартных образцов однозначная идентификация в данном случае затруднена.

Таким образом, полученные данные свидетельствуют о том, что антоциановый состав трех ягод значительно отличается как качественно, так и количественно. Во всех ягодах обнаружены: цианидин-3галактозид, петунидин-3-галактозид и мальвидин-3-галактозид. Соотношение данных антоцианов по процентному содержанию от суммарного содержания антоцианов в ягодах иллюстрирует рисунок 6. Видно, что больше всего цианидин-3-галактозида и мальвидин-3-галактозида содержится в бруснике; петунидин3-галактозида больше всего в клюкве. 


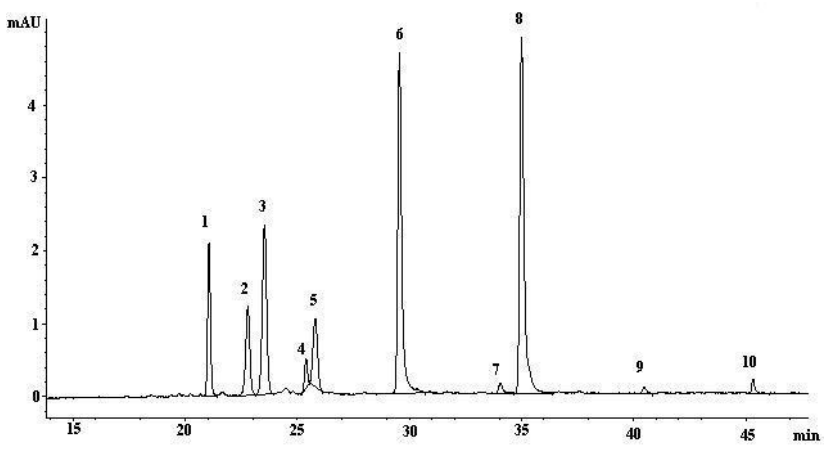

Рис. 5. Хроматограмма антоцианов плодов клюквы обыкновенной

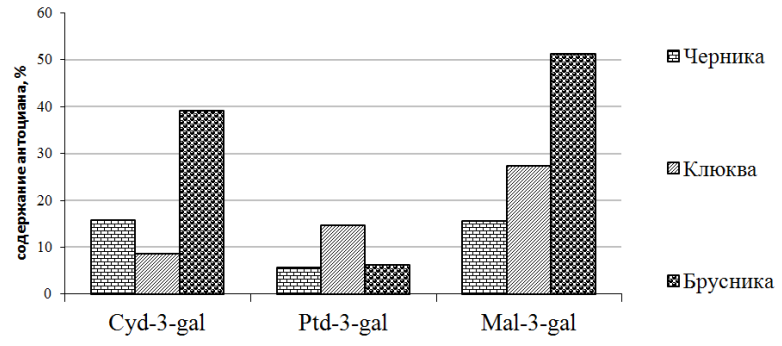

Рис. 6. Процентное содержание антоцианов в ягодах Красноярского края

\section{Bblвodbl}

1. Методом ВЭЖХ с использованием УФ-детектора определен антоциановый состав ягод черники, брусники и клюквы, произрастающих на территории Красноярского края. Определено количественное содержание каждого компонента.

2. Установлены основные различия в антоциановом составе ягод черники, брусники и клюквы Красноярского края.

\section{Список литературы}

1. Охрименко Л.П., Калинкина Г.И., Дмитрук С.Е. Сравнительное исследование толокнянки, брусники и близких к ним видов, произрастающих в республике Саха (Якутия) // Химия растительного сырья. 2005. №1. C. $31-35$.

2. Лютикова М.Н., Туров Ю.П. Компонентный состав свежих, мороженых и подснежных ягод клюквы (Охуcoccus palustris) // Химия растительного сырья. 2011. №4. С. 231-237.

3. Лютикова М.Н. Изучение состава биологически активных компонентов дикорастущих ягод Vaccinium vitisidaea, oxycoccus palustris в зависимости от степени их зрелости и условий хранения : дис. ... канд. хим. наук. Сургут, 2013. 124 c.

4. Кузнецова Н.А. Пищевая ценность соков из дикорастущих ягод клюквы и черники. М., 1975. 33 с.

5. Vorsa N., Polashock J., Cunningham D., Roderick R. Genetic Inferences and Breeding Implications from Analysis of Cranberry Germplasm Anthocyanin Profiles // J. Am. Soc. Hortic. Sc. 2003. Vol. 128. Pp. 691-697.

6. Сергеев В.Н., Кокаев Ю.И. Биологически активное растительное сырье в пищевой промышленности // Пищевая промышленность. 2001. №6. С. 28-30.

7. Рязанова Т.К. Фармакогностическое исследование плодов и побегов черники обыкновенной // Фундаментальные исследования. 2013. №8. С. 1136-1140.

8. Bornsek S.M. Bioefficacy of anthocyanins from bilberries (Vaccinium myrtillus L.) : Doctoral Dissertation. Ljubljana, 2012. $131 \mathrm{p}$.

9. Wu X., Beecher G. R., Holden J. M., Haytowitz D. B., Gebhardt S. E., Prior R L. Concentrations of Anthocyanins in Common Foods in the United States and Estimation of Normal Consumption // J. Agric. Food Chem. 2006. Vol. 54. Pp. 4069-4075.

10. Крупенникова В.Г., Федосеева Г.М. Антоцианы скабинозы венечной // Сибирский медицинский журнал. 2008. №2. С. $78-80$.

11. Дайнека В.И., Григорьев А.М. Определение антоцианов методом высокоэффективной жидкостной хроматографии. Некоторые закономерности удерживания // Журнал аналитической химии. 2004. Т. 59, №3. С. 305-309.

12. Государственная фармакопея СССР / под ред. А.П. Арзамасуев, Н.С. Косырева. М., 1990. 333 с.

13. ГОСТ Р 50521-93. Черника и голубика. Руководство по хранению в холодильных камерах. Введ. 01.01.1994. M., 1994. 4 c.

14. Макаревич А.М., Шутова А.Г., Спиридович Е.В., Решетников В.Н. Функции и свойства антоцианов растительного сырья // Труды БГУ. 2010. Т. 4, вып. 2. С. 1-11.

15. Cassinese C., De Combarieu E., Falzoni M., Fuzzati N., Pace R., Sardone N. New liquid chromatography method with ultraviolet detection for analysis of anthocyanins and anthocyanidins in Vaccinium myrtillus fruit dry extracts and commercial preparations // Journal of AOAC International. 2007. Vol. 90, N4. Pp. 911-919.

16. Anthocyanins Vs Anthocyanidins / Mirtoselect, Indena S.p. A. USA. [Electronic resource]. URL: http://www.mirtoselect.info/public/anthocyanins.asp.

17. Kähkönen M.P., Heinämäki J., Ollilainen V., Heinonen M. Berry anthocyanins: isolation, identification and antioxidant activities // Journal of the Science of Food and Agriculture. 2003. Vol. 83. Pp. 1403-1411. 
Polina S.A., Efremov A.A. ${ }^{*}$ DETERMINATION COMPOSITION OF ANTHOCYANINS IN BILBERRY, COWBERRY AND CRANBERRY WITH HPLC

Siberian Federal University, st. Svobodnyi, 79, Krasnoyarsk, 660041 (Russia),e-mail:AEfremov@sfu-kras.ru

The article contains information about anthocyanin composition of frozen fetuses of bilberry (Vaccinium myrtillus L.), cowberry (Vaccinium vitis idaea L.), cranberry (Vaccinium oxycoccus L.) which grow in Yenisei district of the Krasnoyarsk krai. Determination composition of anthocyanins of berries by HPLC with UV detection. Comparative analysis of the qualitative composition and quantitative content of anthocyanin.

Keywords: Vaccinium myrtillus L., Vaccinium vitis idaea L., Vaccinium oxycoccus L., extract, anthocyanins, HPLC.

\section{References}

1. Okhrimenko L.P., Kalinkina G.I., Dmitruk S.E. Khimiia rastitel'nogo syr'ia, 2005, no.1, pp. 31-35. (in Russ.).

2. Liutikova M.N., Turov Iu.P. Khimiia rastitel'nogo syr'ia, 2011, no. 4, pp. 231-237. (in Russ.).

3. Liutikova M.N. Izuchenie sostava biologicheski aktivnykh komponentov dikorastushchikh iagod Vaccinium vitisidaea, oxycoccus palustris $v$ zavisimosti ot stepeni ikh zrelosti $i$ uslovii khraneniia : dis. ... kand. khim. nauk. [The study of biologically active components of wild berries Vaccinium vitis-idaea, oxycoccus palustris depending on their degree of maturity and storage conditions: the Dissertation of the candidate of chemical sciences]. Surgut, 2013, 124 p. (in Russ.).

4. Kuznetsova N.A. Pishchevaia tsennost' sokov iz dikorastushchikh iagod kliukvy i cherniki. [Nutritional value of juices from wild cranberries and blueberries]. Moscow, 1975, 33 p. (in Russ.).

5. Vorsa N., Polashock J., Cunningham D., Roderick R. J. Am. Soc. Hortic. Sc., 2003, vol. 128, pp. 691-697.

6. Sergeev V.N., Kokaev Iu.I. Pishchevaia promyshlennost', 2001, no. 6, pp. 28-30. (in Russ.).

7. Riazanova T.K. Fundamental'nye issledovaniia, 2013, no. 8, pp. 1136-1140. (in Russ.).

8. Bornsek S.M. Bioefficacy of anthocyanins from bilberries (Vaccinium myrtillus L.): Doctoral Dissertation. Ljubljana, 2012. $131 \mathrm{p}$.

9. Wu X., Beecher G.R., Holden J.M., Haytowitz D.B., Gebhardt S.E., Prior R.L. J. Agric. Food Chem., 2006, vol. 54, pp. 4069-4075.

10. Krupennikova V.G., Fedoseeva G.M. Sibirskii meditsinskii zhurnal, 2008, no. 2, pp. 78-80. (in Russ.).

11. Daineka V.I., Grigor'ev A.M. Zhurnal analiticheskoi khimii, 2004, vol. 59, no. 3, pp. 305-309. (in Russ.).

12. Gosudarstvennaia farmakopeia SSSR. [State Pharmacopoeia of the USSR]. Ed. A.P. Arzamasuev, N.S. Kosyrev. Moscow, 1990, 333 p. (in Russ.).

13. GOST R 50521-93. Chernika i golubika. Rukovodstvo po khraneniiu v kholodil'nykh kamerakh. [State Standard 50521-93 P. Blackberries and blueberries. Guide to storage in refrigerators]. Moscow, 1994, 4 p. (in Russ.).

14. Makarevich A.M., Shutova A.G., Spiridovich E.V., Reshetnikov V.N. Trudy BGU, 2010, vol. 4, no. 2, pp. 1-11. (in Russ.).

15. Cassinese C., De Combarieu E., Falzoni M., Fuzzati N., Pace R., Sardone N. Journal of AOAC International, 2007, vol. 90, no. 4, pp. 911-919.

16. Anthocyanins Vs Anthocyanidins / Mirtoselect, Indena S.p. A. USA. [Electronic resource]. URL: http://www.mirtoselect.info/public/anthocyanins.asp.

17. Kähkönen M.P., Heinämäki J., Ollilainen V., Heinonen M. Journal of the Science of Food and Agriculture, 2003, vol. 83, pp. 1403-1411.

\footnotetext{
* Corresponding author.
} 